\title{
Biomimetic Coating of Precalcified Ti-6Al-4V Alloy
}

\author{
Alaa Adawy ${ }^{1}$, Wafa I. Abd El-Fattah ${ }^{2, *}$, El-Sayed M. El-Sayed ${ }^{1}$ and Mona S.Talaat ${ }^{1}$ \\ ${ }^{I}$ Physics Department, Faculty of Science, Ain Shams University, Cairo, Egypt \\ ${ }^{2}$ Biomaterials Department, National Research Center, Dokki, Cairo, Egypt
}

\begin{abstract}
Calcium hydroxyapatite, $\mathrm{HA},\left(\mathrm{Ca}_{10}\left(\mathrm{PO}_{4}\right)_{6}(\mathrm{OH})_{2}\right)$ bioceramics, owing to their similarity with the human bone and dentin minerals, attract significant interest for orthopaedic and dental applications. Biological apatites, on the other hand, are carbonate substituted and calcium-deficient. Biomimetic coating of titanium and related alloys with carbonated apatitic calcium phosphate is an important area of research in implantology. While this paper specifically refers to coating Ti-6Al-4V, (TAV) the obtained results are valid with other related alloys as well.
\end{abstract}

An attempt was made in the current research to accelerate the biomimetic coating process through precalcification of the alkali and heat treated alloy. The precalcification resulted in a homogenous layer of calcium precursors on the surface of the alloys. Such precursors accelerated the biomimetic deposition of carbonate hydroxyapatite (CHA) coat resembling that of the biomineral apatite upon soaking in Kukubo corrected simulated body fluid $(1.5 \times \mathrm{c}-\mathrm{SBF})$. The development of coats on Ti-6Al-4V surfaces were assessed by step by step diffuse reflectance infra-red spectroscopy and scanning electron microscopy.

The essential information of biodeposition was obtained by following the uptake or release of calcium and inorganic phosphorus, $\mathrm{Ca}$, iP, ionic species biochemically and mirrored by parallel electrical conductivity measurements of the soaking solutions.

Keywords: Ti-6Al-4V, coating, pre-calcification, SBF, electrical conductivity, biomimetic apatite, SEM.

\section{INTRODUCTION}

The interactions of the implant with its biological environment, the formation of a foreign material-tissue interface and the long-term success or failure of the implant-tissue integration are realized to be strongly connected with the surface properties of the implant [1]. The physical, chemical and biochemical properties of the implant surface control the performance of relevant processes such as protein adsorption, cell-surface interaction and cell/tissue development at the interface between the body and biomaterials [2]. Unfortunately, the good degree of biocompatibility and the corrosion durability of titanium alloys don't allow their bonding directly to bone [3]. The bioactivity of metal surface is not high enough to induce growth and fixation of the bone on living tissue.

Therefore, to modify the metal surface becomes an important task when trying to improve bone regeneration $[4,5]$. The coating of the alloy with calcium phosphate compounds, not only does it guarantee a good impermeability of the substrate (metallic implant), to fulfill its task as surfaceprotective-barrier, but induces osseointegration as well.

Therefore, to create a strong orthopedic or dental implant. scientists combine ceramics especially calcium hydroxyapatite, HA, as a coating, demonstrates bioactive

*Address correspondence to this author at the Biomaterials Department National Research Centre, Dokki, Cairo, Egypt, Tel: +20233371414; Fax: 00202 33370931; E-mail: nrcfifi@yahoo.com properties with titanium alloy as a substrate bears the load. In this very successful combination, titanium alloy, providing strength, is coated with HA, which tricks the body by covering up the foreign alloy. Furthermore, as HA breaks down, it tricks the body into building bone tissue around the metallic implant [6].

Many techniques have been used to create ceramic coating on metallic implant materials. Dip coating, electrophoretic deposition, hot isostatic pressing, sol-gel processing, sputter coating and thermal spraying have been used to deposit coatings [7]. On the other hand, the biomimetic coating is a physicochemical method in which a substrate surface is soaked in a solution that simulates the physiologic conditions, for a period of time enough to form a desirable layer of calcium phosphate on the substrate. Advantages of this method are its simplicity and its low investment cost in relation to the plasma spray process usually used. Besides, it can be used to coat substrates with complex geometry or porous substrates, and makes it possible to include organic molecules in the film obtained to induce and accelerate the regeneration of living tissues [8].

Preparation of Ti-6Al-4V to this biomimetic coating process involves several steps. Ultrasonic cleaning, alkali and heat treatment are the usual steps used for this purpose [9]. After these steps, the alloy bears a bioactive surface [10]. Such a surface induces the calcium phosphate deposition upon being soaked in simulated body fluid for at least 14 days [11]. Some attempts were made to accelerate this biomimetic deposition $[12,13]$. 
In this study, an attempt is made to improve and accelerate this coating by combining phosphate and calcium treatments prior to the coating process. This in turn is expected to provide higher coat attachment and coverage.

\section{MATERIALS AND METHODOLOGIES}

Ti-6Al-4V discs were purchased from a local producing company. All samples have the same dimensions $(0.61 \mathrm{~cm}$ in diameter and $0.1 \mathrm{~cm}$ in thickness). Their weights are $0.22 \mathrm{gm}$ $\pm 0.01 \mathrm{gm}$. The discs were polished to mirror image at one surface and the other was roughened to an average surface roughness of $35 \mu \mathrm{m}$.

Prior to precalcification, these discs were subjected to the following treatments:

\section{a) Ultrasonic Cleaning}

The samples were washed first in acetone (Silver Star, M.W. $=58.08 \mathrm{gm}$, extra pure) for 15 minutes, then in ethanol (ADWIC, M.W. = 46.07gm, absolute) for another $15 \mathrm{~min}$ utes and finally in double distilled water (Shanghai Sanshen medical instrument Co. LTD) for 15 more minutes. The cleaning procedure was maintained at a temperature of $45^{\circ} \mathrm{C}$ in the ultrasonic cleaner (ultrasonic cleaning technology, model 300, $140 \mathrm{watt} / \mathrm{cm}^{2}, 22 \mathrm{KHz}$ ).

\section{b) Alkali Treatment}

Each sample was then placed in a glass sealed flask containing the $5 \mathrm{M} \mathrm{KOH}$ solution. Typically, each disc was immersed in $27.65 \mathrm{ml}$ of $\mathrm{KOH}$ solution at $60^{\circ} \mathrm{C}$ for 24 hours. The samples were then gently washed with double distilled water. Finally, they were dried overnight at $40^{\circ} \mathrm{C}$.

\section{c) Heat Treatment}

The heat treatment was performed at $600^{\circ} \mathrm{C}$ in an air atmosphere furnace, (DAIHAN LABTEECH CO.LTD). The samples were heated with an average heating rate of $3^{\circ} \mathrm{C} / \mathrm{min}$ up to $600^{\circ} \mathrm{C}$ and kept for 1 hour. Then they were allowed to cool overnight.

\section{Precalcification}

The pre-calcification process was classified into two parts. The first part was the immersion of the samples in the phosphorus containing solution, $0.6 \mathrm{M} \mathrm{Na} \mathrm{HPO}_{4}$ (Panreac, M.W. $=174.18 \mathrm{gm}, 99 \%$ ). Each sample was immersed in a sealed glass flask containing $39 \mathrm{ml}$ of this solution and left overnight. They were removed and gently rinsed three times with double distilled water. Samples coded as (SAHP) $[P$ stands for phosphorus], were dried at $40^{\circ} \mathrm{C}$ to be ready for characterizations. The rest of samples were boiled for 45 minutes in supersaturated calcium hydroxide solution, $\left(\right.$ AnalaR $^{\circledR}$, M.W. $\left.=74.10 \mathrm{gm}, 98 \%\right)$. The samples were again gently rinsed three times with double distilled water and left to dry at ambient temperature. A group of them was coded as (SAHPC) [C stands for calcium] were dried at $40^{\circ} \mathrm{C}$ to be ready for characterizations (Table 1).

\section{Biomimetic Soaking}

The pretreated samples were soaked in a supersaturated solution leading the ionic concentration of the ordinary SBF solution by one half, $1.5 \times \mathrm{c}-\mathrm{SBF}$. The reagents used to prepare one litre are sodium chloride, $\mathrm{NaCl}$ (Merck, M.W. =
Table 1. Codes and Description for all Samples of the Successive Steps

\begin{tabular}{|c|c|}
\hline Code & Description \\
\hline \hline SZ & Ultrasonically cleaned Ti-6Al-4V discs \\
\hline SA & Ultrasonically cleaned and alkali treated Ti-6Al-4V discs \\
\hline SAH & SA heat treated at $600{ }^{\circ} \mathrm{C}$ \\
\hline SAHP & SAH immersed in phosphorus containing solutions \\
\hline SAHPC & SAHP immersed in calcium containing solution \\
\hline c-SBF & SAHPC soaked in $1.5 \times$ c-SBF \\
\hline
\end{tabular}

$58.44 \mathrm{gm} / \mathrm{mole}$, extrapure); sodium hydrogen carbonate, $\mathrm{Na}$ $\mathrm{HCO}_{3}(\mathrm{Gen} \mathrm{Lab}, \mathrm{M} . \mathrm{W} .=84.01 \mathrm{gm} / \mathrm{mole}$, 99\%); potassium chloride, $\mathrm{KCl}$ (SISCO, M.W. = $74.55 \mathrm{gm} / \mathrm{mole}$, extrapure); dipotassium hydrogen phosphate, (SISCO, M.W. = $174.18 \mathrm{gm} / \mathrm{mole}, 99 \%)$; magnesium chloride six hydrate, $\mathrm{MgCl}_{2} .6 \mathrm{H}_{2} \mathrm{O}$ (ADWIC, M.W. = 203.3gm, 97\%); calcium chloride, $\mathrm{CaCl}_{2}$ (Gen Lab, M.W. = 110.99gm $/ \mathrm{mole}, 99 \%$ ); sodium sulphate anhydrous and $\mathrm{Na}_{2} \mathrm{SO}_{4}$ (Modern lab, M.W. $=142.04 \mathrm{gm}$, extra pure). Tris (hydroxymethyl) amino methane, $\left(\mathrm{CH}_{2} \mathrm{OH}\right)_{3} \mathrm{CNH}_{2}$ (Fluka Biochemika, M.W. = $121.14 \mathrm{gm} / \mathrm{mole}, 99 \%$ ) was used as a buffering agent. The $\mathrm{pH}$ value of the prepared solution was kept at $7.3 \pm 1$ at $37 \pm 1^{\circ} \mathrm{C}$. The order and weights of each reagent are given in Table (2).

This solution was designed according to Kokubo et al. (c-SBF). The low concentration of the hydrogen carbonate content compared to the level that mimics its level in the extracellular fluid was adopted. Recent researches confirmed that raising the concentration of hydrogen carbonate content in SBF reduces its stability greatly [14]. Besides, decreasing $\mathrm{HCO}_{3}{ }^{-}$was valuable in the current case where the ions concentrations are already higher by one half than theirs in the extracellular fluid. In addition, buffering was mediated by Tris buffer not HEPES buffer, applied in the revised SBF (rSBF) [15].

Table 2. Reagents Used in preparation of $1.5 \times \mathrm{c}-\mathrm{SBF}$

\begin{tabular}{|c|c|c|}
\hline Order & Reagent & Weight(gm) \\
\hline \hline 1 & $\mathrm{NaCl}$ & 12.0525 \\
\hline 2 & $\mathrm{NaHCO}_{3}$ & 0.5325 \\
\hline 3 & $\mathrm{KCl}$ & 0.3375 \\
\hline 4 & $\mathrm{~K}_{2} \mathrm{HPO}_{4}$ & 0.2554 \\
\hline 5 & $\mathrm{MgCl}_{2} \cdot \mathrm{H}_{2} \mathrm{O}$ & 0.4665 \\
\hline 6 & $1 \mathrm{M} \mathrm{HCl}$ & $58.5 \mathrm{ml}$ \\
\hline 7 & $\mathrm{CaCl}_{2}$ & 0.4380 \\
\hline 8 & $\mathrm{Na}_{2} \mathrm{SO}_{4}$ & 0.1080 \\
\hline 9 & $\left(\mathrm{CH}_{2} \mathrm{OH}\right)_{3} \mathrm{CNH}_{2}$ & 9.1770 \\
\hline 10 & $1 \mathrm{M} \mathrm{HCl}$ & $0-7.5 \mathrm{ml}$ \\
\hline
\end{tabular}




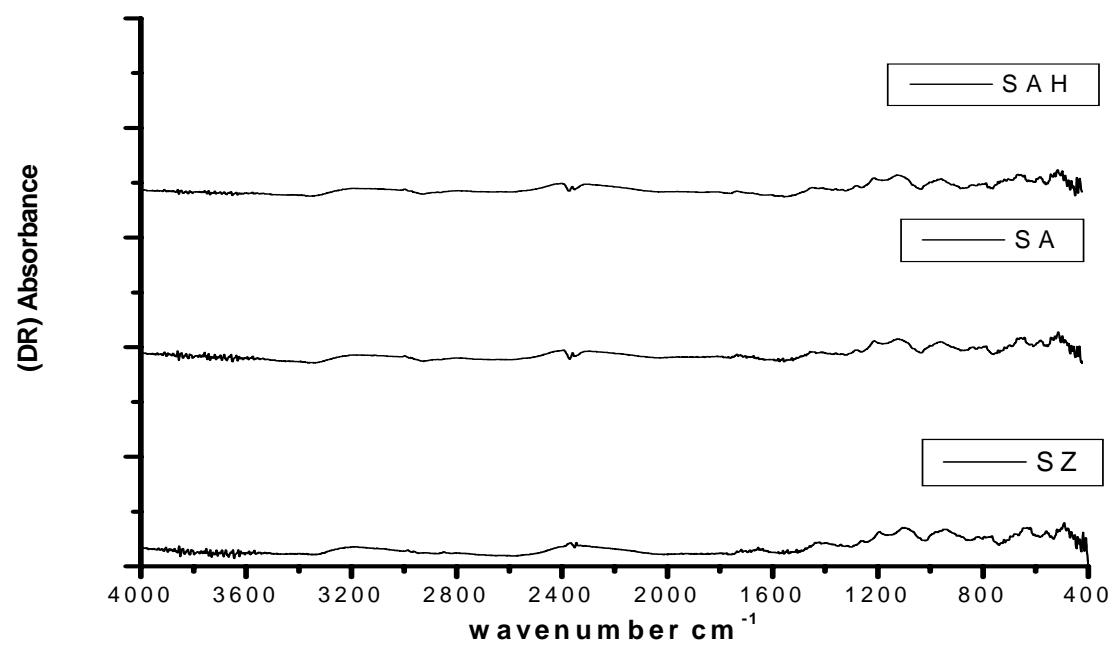

Fig. (1). Diffuse reflectance FT-IR charts for Ti-6Al-4V alloy after ultrasonic cleaning: SZ, alkali treatment: SA and heat treatment: SAH.

\section{Coating Procedure}

Each sample was immersed vertically in the solution to avoid the aggregation of the solution precipitates-if any- on its surface. These precipitates would hide the sample surface and inhibit the real nucleation. According to Kokubo's design of the apatite forming ability test, for dense materials, the volume of SBF used is calculated according to the following equation

$$
V_{s}=\frac{S_{a}}{10}
$$

Where $\mathrm{V}_{\mathrm{s}}$ is the volume of SBF (ml) and $\mathrm{S}_{\mathrm{a}}$ is the apparent surface area of the sample $\left(\mathrm{mm}^{2}\right)$.

For the present disc shaped samples whose apparent surface area could be summarized as $77.6 \mathrm{~mm}^{2}$, the needed volume of SBF for soaking each sample is $8 \mathrm{ml}$ to satisfy a ratio of 10:1. Therefore, every sample was soaked in a freshly prepared solution, kept at $36.5^{\circ} \mathrm{C}$ using a water bath for up to 10 days. Replenishment was done for the soaking solution every 2 days. After the completion of the soaking periods, the samples were gently rinsed with double distilled water and were left to dry at ambient room temperature.

\section{Characterizations}

\section{Biochemical Analyses}

These analyses are assumed to give the complementary information. It is supposed that any decrement occurs in the solution ionic concentration, is suggested to be a build on to the substrate.

The variation of calcium and phosphorus concentrations of solutions throughout successive soaking periods was measured using biochemical kits and spectrophotometer 6100, Type M 129 Jenway LTD - UK. For mother solutions, the results gave approximately the same concentration as it was calculated during their preparation assuring, therefore, the validity of the tests.

\section{Surface Chemical Analysis}

Infra-red analysis of Ti-6Al-4V disc surfaces was assessed using the diffuse reflectance fourier transform infrared spectroscopy (FT-IR 6100 JASCO, DR-81).

\section{Electrical Measurements}

The solutions after each soaking step were tested by measuring the conductivity of various soaking solutions from periods with reference to mother solutions to assess the ion release from or uptake to the treated substrates. Conductivity was measured using a conductance bridge (Griffin and George LTID) and a glass conductance cell made up of fused silica. It contains two platinum disc electrodes of $0.785 \mathrm{~mm}^{2}$ in cross sectional area and separated by a fixed distance at $2 \mathrm{~mm}$, connected to the bridge.

\section{Morphological Investigations}

The coatings were examined using SEM (JEOL JXA$840 \mathrm{~A}$ electron probe micro analyzer). An accelerating voltage of $30 \mathrm{KeV}$ was used. The samples were sputter-coated with gold before examination.

\section{RESULTS}

\section{Surface Chemical Analysis}

\section{Pretreatments}

Alkali treated (SA) samples were examined using FT-IR spectroscopy, comparing to that of ultrasonically cleaned (SZ) samples, and no differences for both charts could be observed. In the same manner, FT-IR chart of alkali and heat treated samples (SAH) show no difference from both of(SZ) and (SA )in the range of $4000-400 \mathrm{~cm}^{-1}$ (Fig. 1).

\section{Precalcification}

The FT-IR chart post phosphate treatment, (SAHP), doesn't show differences from that of previous ones. Whereas, FT-IR chart post calcium treatment, (SAHPC), is completely different, (Fig. 2). A sharp small peak appeared at $3638 \mathrm{~cm}^{-1}$ which accounts for $\mathrm{OH}^{-}$stretching vibration. 


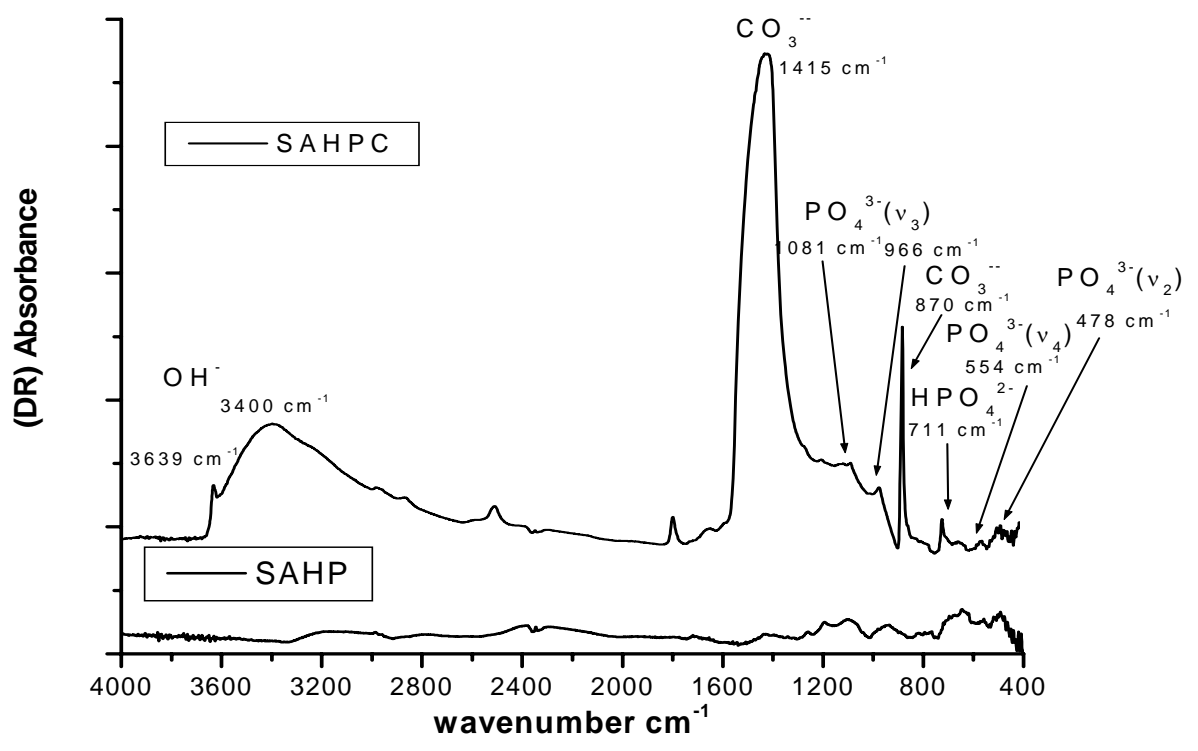

Fig. (2). Diffuse reflectance FT-IR charts for Ti-6Al-4V alloy after precalcification: subsequent immersion in phosphorus (SAHP) followed by calcium containing solutions (SAHPC).

Another relatively large band appeared at $3408 \mathrm{~cm}^{-1}$ is also related to $\mathrm{OH}^{-}$stretching band [16-21].

A very large peak appearing at $1428 \mathrm{~cm}^{-1}$, can be attributed to generic " $\mathrm{C}-\mathrm{O}$ " stretch $v_{3}$, indicating the presence of large amount of $\mathrm{CO}_{3}{ }^{2-}$ in the resultant phase. At $868 \mathrm{~cm}^{-1}$, a very sharp peak appeared and is assigned to "out-of-plane" $\mathrm{C}-\mathrm{O}$ bending vibration $v_{2}[16,22,23]$. Besides, a peak appeared at $710 \mathrm{~cm}^{-1}$, is assigned to "in-plane" C-O bending vibration. Such peaks as a whole assure the presence of inorganic $\mathrm{CO}_{3}{ }^{2-}$ group $[18,19,22,24,25]$.

The high carbonate content in the resultant phase is explained by the partial ability of $\mathrm{CO}_{2}$ to dissolve in water, and in basic solution its solubility increases. During precalcification, $\mathrm{CO}_{2}$ in air dissolved into $\mathrm{Ca}(\mathrm{OH})_{2}$ solution and transformed to $\mathrm{CO}_{3}{ }^{2-}$ ions, and subsequently coprecipitated with $\mathrm{Ca}^{2+}$ or adsorbed onto titanium forming $\mathrm{CaCO}_{3}$. The $\mathrm{CO}_{3}{ }^{2-}$ in the resultant surface structure substitutes for the $\mathrm{OH}^{-}$or $\mathrm{PO}_{4}{ }^{3-}$ in $\mathrm{Ca}$-deficient apatite crystal lattice.

In the range of $1200-960 \mathrm{~cm}^{-1}$, which indicates the presence of $\mathrm{PO}_{4}{ }^{3-}$, small peaks appeared around $1086 \mathrm{~cm}^{-1}$, as short band along with another sharp one at $967 \mathrm{~cm}^{-1}$. Both peaks are assigned to $\mathrm{PO}_{4}{ }^{3-}$ stretching vibration $v_{3}$ and $v_{1}$ respectively. This shows the growth of an apatite phase on the surface. Peaks at $560 \mathrm{~cm}^{-1}$, assigned for $\mathrm{PO}_{4}{ }^{3-}$ bending vibration $v_{4}$ and around $470 \mathrm{~cm}^{-1}$ are indicating the growth of $\mathrm{PO}_{4}{ }^{3-}$ bending vibration $v_{2}[16-19,21,22,26]$. Therefore, the overall pattern is attributed for the growth of a carbonated amorphous calcium phosphate, where the carbonate groups dominated much over the phosphate sites in the resultant phase $[20,25,27,28]$. This ensures the deposition of calcium carbonate phase on the surface of the pretreated TAV alloy.

\section{Biomimetic Coating}

After the vertical immersion of SAHPC samples in $1.5 \times$ SBF for two successive soaking periods each of two days, i.e., 4 days, at $37^{\circ} \mathrm{C}$, the resultant FT-IR chart showed resorption of the peak values with respect to precalcified samples (Fig. 3). All peaks were approximately at similar positions as that of precalcified samples. Interesting is the dramatic decrease in all the values specially that of $\mathrm{CO}_{3}{ }^{2-}$ which become also sharper. In addition, the sharp peak appeared at 3638 $\mathrm{cm}^{-1}$ after precalcification vanishes completely. An overall increase of the absorption around $500 \mathrm{~cm}^{-1}$ without specification of certain peaks is recorded when compared to that of the pervious step. This may accounts for the release of excess ions previously precipitated on the sample surface post the precalcification step.

After the third soaking period, (Fig. 3), the peaks started to rebuild again. The band around $3408 \mathrm{~cm}^{-1}$, related to $\mathrm{OH}^{-}$ stretching band started to grow again. Another one at 1644 $\mathrm{cm}^{-1}$, related to O-H scissors, together with the former assure the presence of water molecules accompanying the inorganic calcium phosphate phase, (Fig. 3), [16, 18-20, 28, 29].

The large sharp peak appearing at $1403 \mathrm{~cm}^{-1}$, can be attributed to generic "C-O" stretch $v_{3}$, indicating the presence of $\mathrm{CO}_{3}{ }^{2-}$ in the resultant phase, but still lower than that corresponding to the precalcification step, (Fig. 2), [21, 23, 25, 30]. At $873 \mathrm{~cm}^{-1}$, a very sharp peak appeared and is assigned to "out-of-plane" C-O bending vibration $v_{2}$. Besides, a small peak appeared at $710 \mathrm{~cm}^{-1}$, is assigned to "in-plane" C-O bending vibration. Such peaks assure the presence of inorganic $\mathrm{CO}_{3}{ }^{2-}$ group $[16,18,19,22,25,28]$.

At the area assigned for $\mathrm{PO}_{4}{ }^{3-}$ a large peak appeared around $1027 \mathrm{~cm}^{-1}$, in which the small peak at $962 \mathrm{~cm}^{-1}$ seems to be dissolved in. Such peak is assigned to $\mathrm{PO}_{4}{ }^{3-}\left(v_{3}\right)$ stretching vibration. Small peaks at $606 \mathrm{~cm}^{-1}$ and $562 \mathrm{~cm}^{-1}$, assigned for $\mathrm{PO}_{4}{ }^{3-}\left(v_{4}\right)$ bending vibration, and around $474 \mathrm{~cm}^{-1}$ indicate the growth of $\mathrm{PO}_{4}{ }^{3-}\left(v_{2}\right)$, which started to grow and become more differentiated, (Fig. 3), [16, 18, 19, 21, 22, 25, 26]. Therefore, the growth of a carbonated hydroxyapatite, where the carbonate groups have grown together with the phos- 


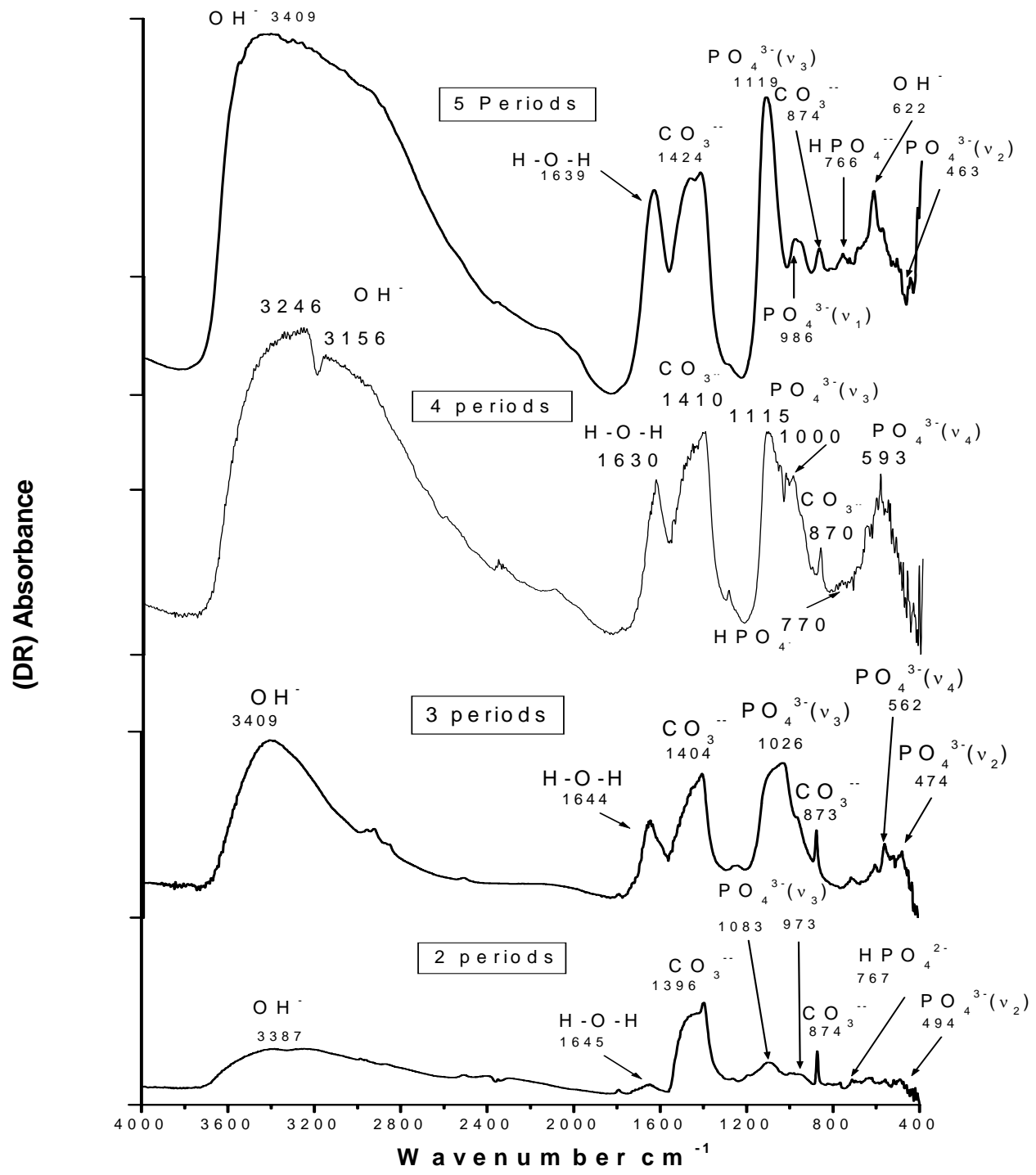

Fig. (3). Diffuse reflectance FT-IR charts for c-SBF after 2, 3, 4 and 5 soaking periods of biomimetic soaking in $1.5 \times \mathrm{c}-\mathrm{SBF}$.

phate sites in the resultant phase, i.e., Type B, can be concluded [18]. Nevertheless, the presence of the doublet of $873 \mathrm{~cm}^{-1}$ and $962 \mathrm{~cm}^{-1}$ indicate the presence of $\mathrm{HPO}_{4}{ }^{2-}$ in the resultant coating [20, 28].

After the fourth soaking period, (Fig. 3), the resultant bands prove growth and more differentiation for all the peaks. The water band increased greatly and started to be differentiated into two parts centered around $3246 \mathrm{~cm}^{-1}$. Besides, the peak assigned for $\mathrm{O}-\mathrm{H}$ scissors exhibited a red shift from $1644 \mathrm{~cm}^{-1}$ to $1630 \mathrm{~cm}^{-1}$ and increased greatly.

The large sharp peak attributed to generic "C-O" stretching has undergone a violet shift from $1403 \mathrm{~cm}^{-1}$ to $1408 \mathrm{~cm}^{-1}$, but still its value doesn't reach that resulted after the precalcification step. At $869 \mathrm{~cm}^{-1}$, the very sharp peak assigned to "out-of-plane" C-O bending vibration, continued its growth. Besides, the small peak appeared at $710 \mathrm{~cm}^{-1}$ after the third soaking period vanished here.

At the space assigned for $\mathrm{PO}_{4}{ }^{3-}$ a large band appeared between $1118 \mathrm{~cm}^{-1}$ and $1000 \mathrm{~cm}^{-1}$. It is assigned to $\mathrm{PO}_{4}{ }^{3-}\left(v_{3}\right)$ stretching vibration. The peak centered around $593 \mathrm{~cm}^{-1}$, assigned for $\mathrm{PO}_{4}{ }^{3-}\left(v_{4}\right)$ bending vibration, and a very sharp one at $470 \mathrm{~cm}^{-1}$ indicate the growth of $\mathrm{PO}_{4}{ }^{3-}\left(v_{2}\right)$, continue their growth and differentiation.

After the fifth soaking period, (Fig. 3), the resultant FTIR chart shows stability in the values of most of the peaks, with respect to the previous soaking one. The ratio of carbonate to phosphate value changed with an excess for the latter is proved.

$\mathrm{O}-\mathrm{H}$ band started around $3553 \mathrm{~cm}^{-1}$ and end at $2859 \mathrm{~cm}^{-1}$ increased slightly with respect to that of the previous soaking period. Similarly, the peak assigned for $\mathrm{O}-\mathrm{H}$ scissors show a violet shift to $1639 \mathrm{~cm}^{-1}$. A peak centered at $622 \mathrm{~cm}^{-1}$, is assigned for $\mathrm{OH}^{-}$bending vibration: liberation mode of HA. It has been claimed that abundant hydroxyl groups on the titanium surfaces are essential to the bioactivity of titanium [31].

The large peak attributed to generic "C-O" stretch becomes more broadened, undergoes a violet shift and grows more differentiated into two separated ones at $1471 \mathrm{~cm}^{-1}$ and $1424 \mathrm{~cm}^{-1}$. Nevertheless, the values of such peaks haven't reached that resulted after the precalcification step, and are still within the same value for those of the fourth soaking 

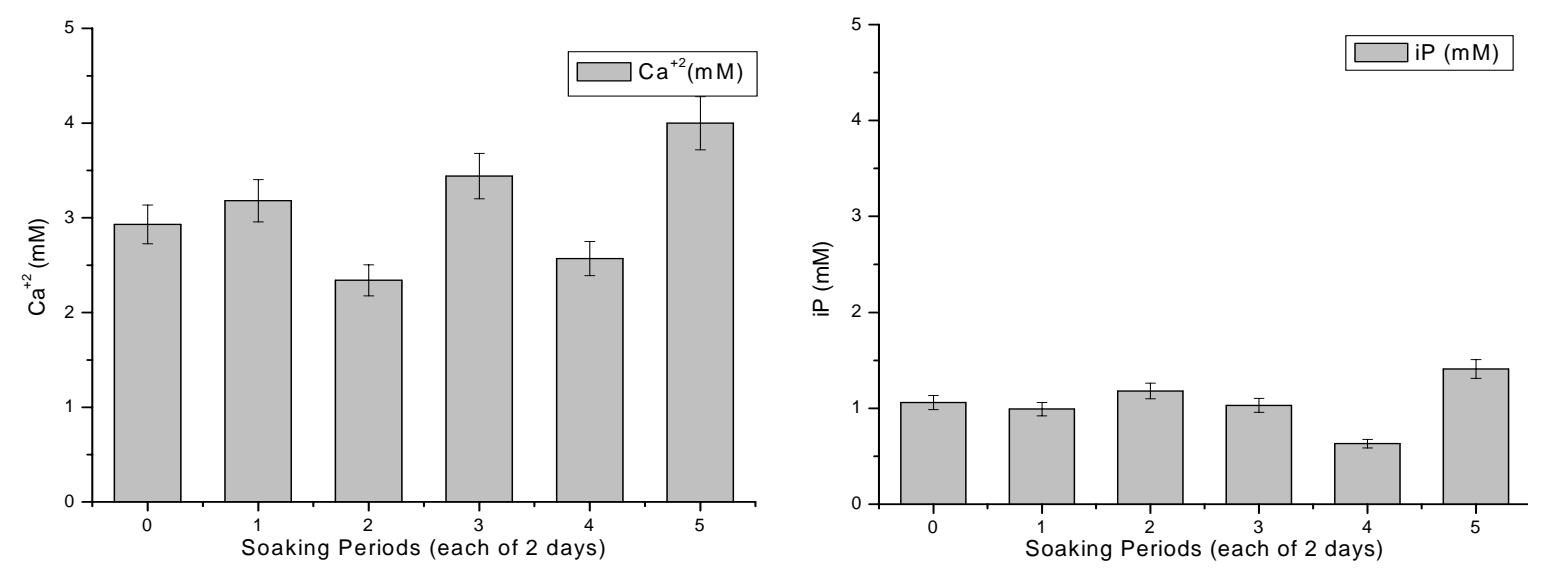

Fig. (4). The concentrations of calcium and inorganic phosphorus ions (mM) through successive soaking periods.

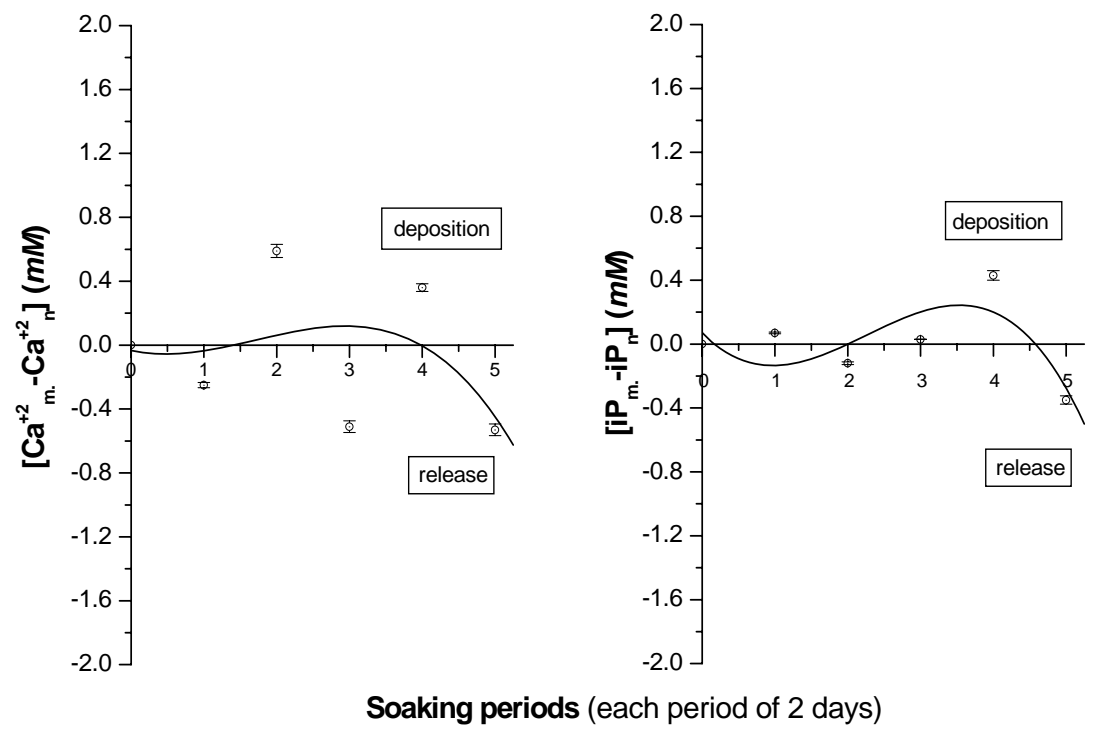

Fig. (5). Uptake of $\mathrm{Ca}^{+2} \&$ iP onto SAHPC samples from $1.5 \times \mathrm{c}-\mathrm{SBF}$ solution through various soaking periods with respect to the mother solution. (Where, $\mathrm{Ca}_{\mathrm{m}}^{+2} \& \mathrm{iPm}$ are for mother solution, while, $\mathrm{Ca}_{\mathrm{n}}^{+2} \& \mathrm{iP}_{\mathrm{n}}$ are specific for each period) (The drawn curve represents the polynomial fitting of the third order to the obtained results).

period. At $874 \mathrm{~cm}^{-1}$ the very sharp peak assigned to "out-ofplane" C-O bending vibration, continued its growth. Besides, the small peak appeared at $710 \mathrm{~cm}^{-1}$ after the third soaking period continued its vanishing in this chart. The carbonate content here is ascribed to B-type carbonate which substitutes for phosphate groups rather than hydroxyl ones [21].

At the space assigned for phosphate groups, an increased growth in all peaks occurred. The large band appearing after the fourth soaking period grew and differentiated into two separate ones at $1118 \mathrm{~cm}^{-1}$, phosphate $v_{3}$, and at $986 \mathrm{~cm}^{-1}$, phosphate $v_{1}$. A very sharp peak at $462 \mathrm{~cm}^{-1}$ indicating the growth of phosphate $v_{2}$, continued its growth and became more differentiated. Therefore, the growth of a biomimetic carbonated apatite, HCA, can be assured [20, 21].

\section{Biochemical Analysis}

The ionic concentrations of calcium and inorganic phosphorus are shown in Fig. (4). When studying the changes in calcium and phosphorus concentration through successive soaking periods, an ideal behavior for calcium phosphate phase deposition is recorded, (Fig. 5). Based on both calcium and phosphorus uptake onto the samples, any change either by decrease or increase in calcium or phosphorus ionic concentration, with respect to mother solution indicate a deposition or release on or from the SAHPC sample surface respectively. Interestingly, the behavior of $\mathrm{Ca}^{+2}$ and iP was opposite to each other through first three soaking periods then started to go in parallel through the rest of soaking periods. The opposition in $\mathrm{Ca}^{+2}$ and iP behaviors is a natural form, where the deposition of calcium is followed by that of phosphorus to the sample surface successively and not instantaneously. After the first soaking period, the uptake of calcium becomes of a negative value, i.e., release of calcium from the sample surface, (Fig. 5). This may be due to the saturation of the samples by $\mathrm{Ca}^{+2}$ through the previous precalcification treatment [13]. An uptake of calcium was accompanied by a release of phosphorus. At the fifth soaking period, both the calcium and phosphorus show release, i.e., values increase. 


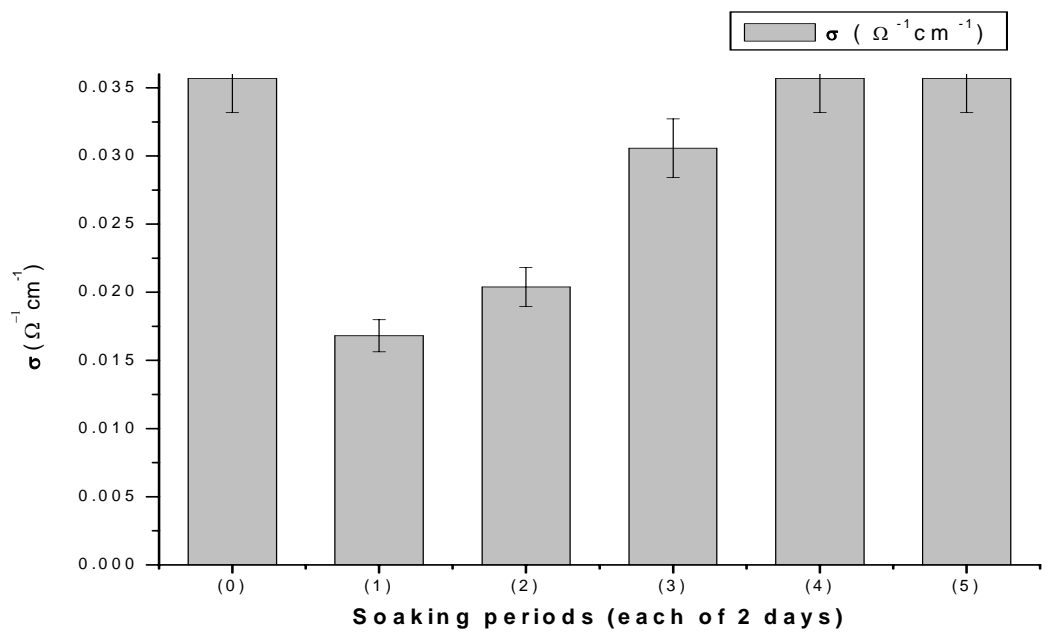

Fig. (6). The values of electrical conductivity, $\sigma$, through the successive soaking periods.

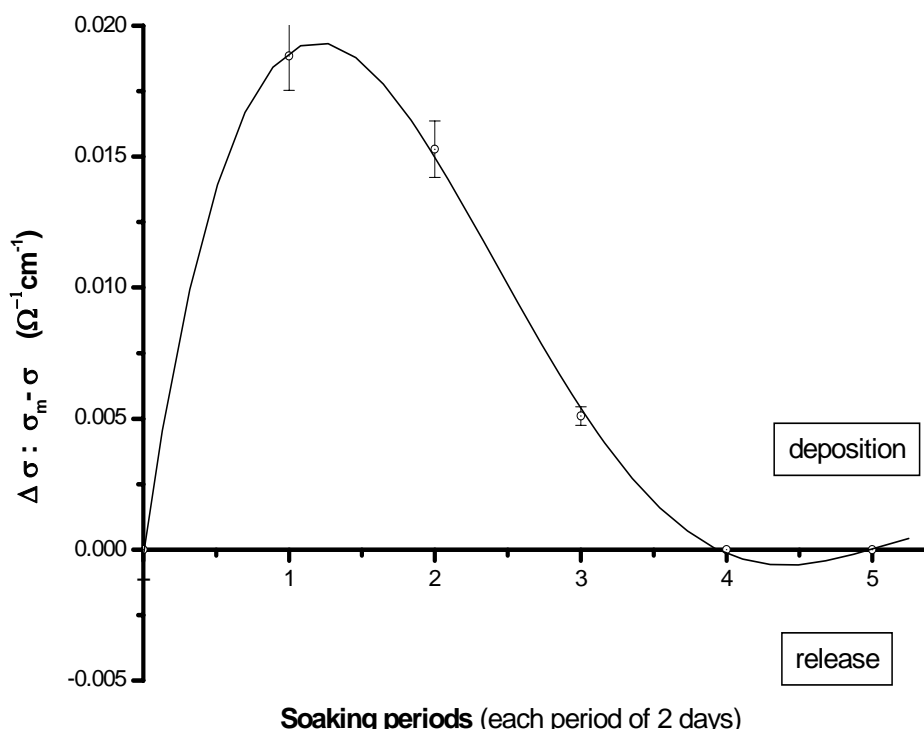

Fig. (7). Decrement in conductivity, $\Delta \sigma$, of $1.5 \times \mathrm{c}-\mathrm{SBF}$ through various soaking periods with respect to the mother solution. (Where $\sigma_{\mathrm{m}}$ is the conductivity of the mother solution and $\sigma_{\mathrm{n}}$ is the conductivity of respective time interval). (The drawn curve represents the polynomial fitting of fourth order to the obtained results) excessive deposition in early $48 \mathrm{hrs}$.

This is a result of the surface saturation of alloys. This is confirmed by the DR-FTIR after this period, where the bands settled at relatively the same values of the fourth soaking period, (Fig. 3).

\section{Electrical Conductivity}

The values of electrical conductivity for successive soaking solutions account for ionic concentrations of these supersaturated solutions, (Fig. 6). The decrement was maximal at the first soaking period, (Fig. 7), due to the deposition of these ions onto the sample surface. Then its value started to decrease, successively through soaking periods until it completely stopped at the fourth one, proving completion of deposition. Through the fourth and fifth soaking periods, apparently, there was negligible change in conductivity values with respect to that of the mother $1.5 \times \mathrm{c}-\mathrm{SBF}$, i.e., the process appears to be an ionic exchange rather than only calcium phosphate deposition. This accounts for the presence of other ions in such supersaturated solution rather than calcium and phosphorus from $1.5 \times \mathrm{c}-\mathrm{SBF}$ and the alloy surface.

\section{Morphological Investigation \\ SAHPC Samples}

The surface morphology of the SAHPC proves that the sample surface is completely covered with a dense and uniform calcium phosphate film, Fig. (8). Such globules have completely covered the alloy surface although seem rough but it is a uniform distribution). At higher magnification, (Fig. 8-b), the originally rough surface of the alkali and heat treated sample completely changed into a microporous surface by the precalcification. The pore sizes are on submicron 

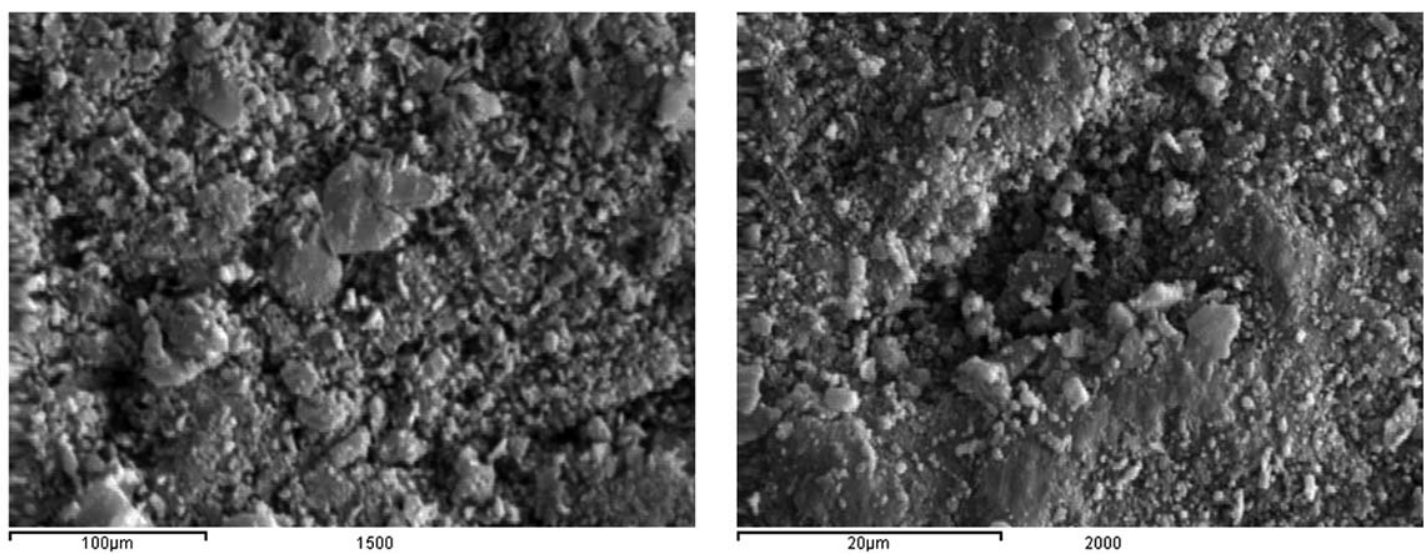

Fig. (8). SEM micrographs of precalcified Ti-6Al-4V samples at $1500 \mathrm{x}$ : bar $=100 \mu \mathrm{m}$ and $2000 \mathrm{x}$ : bar $=20 \mu \mathrm{m}$.
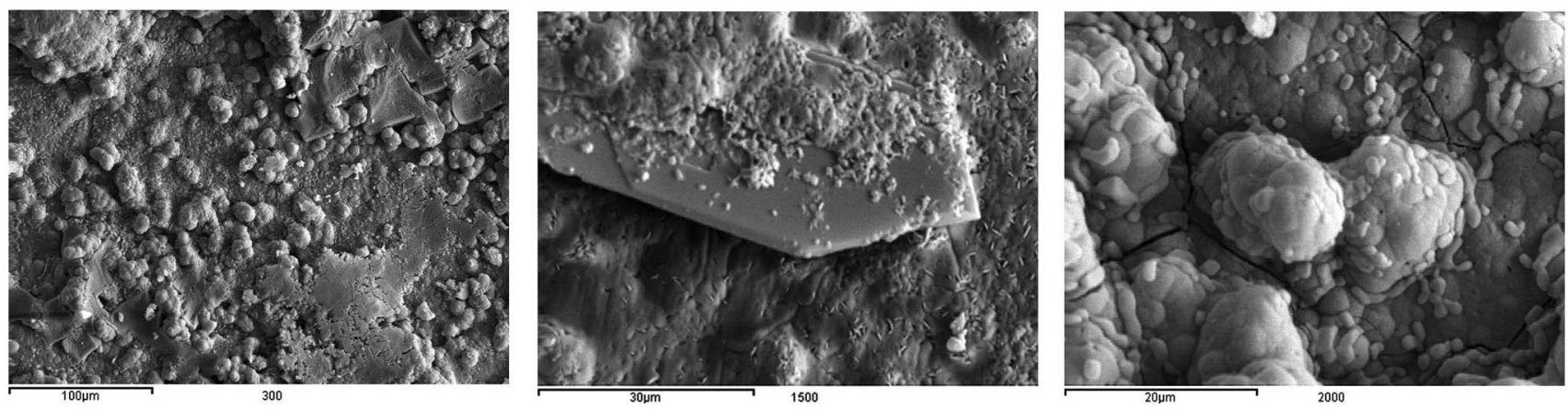

Fig. (9). SEM micrographs of c-SBF samples post 5 periods soaking at 300x: bar $=100 \mu \mathrm{m}$, showing an overall view; $1500 \mathrm{x}$ : bar $=30 \mu \mathrm{m}$, showing the plate like structures and at $2000 \mathrm{x}$ : bar $=20 \mu \mathrm{m}$, showing the spherical HA globules.

scale. The surface is full of small plate like structures rather than spherical ones. The attachment of these particles on the surface could be attributed to the retrograde solubility of calcium hydroxide in water with increasing temperature and also to the reaction of calcium compounds with the titanium surfaces [13].

\section{c-SBF Samples}

The surface morphology of c-SBF sample after five successive periods of biomemetic soaking in $1.5 \times \mathrm{c}-\mathrm{SBF}$ is shown in Fig. (9). The coating revealed a uniform distribution of calcium phosphate layer deposited all over the surface. The deposits show multilayer pattern. This may be a result of the successive replenishment of the biomimetic soaking solutions [17]. The plate-like apatite structures continued their appearance together with spheroid globules. They show plate-like structures with a growth in their sizes compared to that observed on SAHPC, (Fig. 8). At still higher magnifications, the spheroid globules show agglomerations, indicating homogenous nucleation and subsequent deposition of calcium phosphate [32]. These globules, about $10 \mu \mathrm{m}$ in diameter, are located on the top of the early formed undercoat-like layer. The globules appear to consist of small spherical crystals, approximately $1-2 \mu \mathrm{m}$ in diameter. The resultant surface confirms the success of biomimetic carbonate apatite coating of Ti-6Al-4V [33, 34].

\section{DISCUSSION}

\section{Importance of the Pretreatments}

Upon alkali treating the substrates in $5 \mathrm{M} \mathrm{KOH}$ at $60^{\circ} \mathrm{C}$ for 24 hours, a titanate hydrogel layer is formed on the metal surface, in which negatively charged $\mathrm{HTiO}_{3}{ }^{-}+\mathrm{nH}_{2} \mathrm{O}$ incorporating potassium ions can be found. Illustration of the chemical reactions is as follow: $[35,36]$

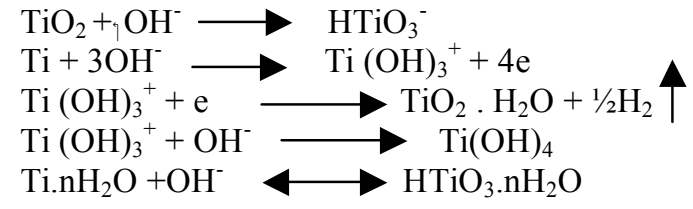

A subsequent heat treatment dehydrates this hydrogel layer and stabilizes it by the formation of an amorphous sodium titanate layer $\left(\mathrm{HTiO}_{3} \mathrm{Na}\right)$, [37]. Finally, the sodium ions in the surface layer will replace the $\mathrm{H}_{3} \mathrm{O}^{+}$ion in SBF, producing $\mathrm{Ti}-\mathrm{OH}$ groups on the surface of the titanium to induce the apatite nucleation, [35].

The infra-red spectroscopy investigation of pretreatments including ultrasonic cleaning, alkali and heat treatments didn't show real differences. This may be related to the evaporation of water content in the hydrogel layer that would otherwise appear as a large band around $3200 \mathrm{~cm}^{-1}$. Drying 
the samples after being alkali-treated with $\mathrm{KOH}$ would stabilize the potassium titanate gel grown on the surface and evaporated the water content $[38,39]$. It was reported that the alkali treatment of the alloy surface not only does it enhance surface bioactivity but also improves the hydrophilicity. Such a property was attributed to the change of the surface function groups during the alkali treatment. This superhydrophilicity of alkali treated surfaces ensures the uniform coating formation on the alloy surface [40]. Heat treatment of the samples at $600^{\circ} \mathrm{C}$ was set to completely stabilize the amorphous potassium titanate phase grown on the sample surface [38]. By combining the alkali and heat treatment, the surface is made both harder and bioconductive and a layer of calcium phosphate can be easily induced on the alloy surface [41].

\section{The Validity of Precalcification}

Generally, the concentration variations through different soaking periods confirm the calcium phosphate deposition on to SAHPC samples. It is suggested that $\mathrm{Ca}(\mathrm{OH})_{2}$, and a small amount of $\mathrm{CaCO}_{3}$ deposited on the surfaces through the precalcification, would partially dissolve into the aqueous solution, SBF, and thus, the solubility product, or the supersaturating level with respect to apatite further increased. Moreover, because of the abundant $\mathrm{Ca}^{2+}$ on the precalcified surface, $\mathrm{PO}_{4}^{-3}$ should be easily adsorbed and transformed to calcium phosphate crystal nuclei. Obviously, these crystal nuclei formed are of larger particles than those formed on the plane sample. Since large crystal grains have lower surface energy and are more stable, then according to classic surface chemistry, calcium and phosphate ions in the solution would be more easily precipitated onto them and crystallize [13].

In addition, with a number of calcium ions, the surfaces of precalcificated titanium should be charged positively in bioliquid with $\mathrm{pH}$ 7.2-7.4. Therefore, it would adsorb negative ions, such as phosphate ions and hydroxyl groups by Coulomb force. The function of Ti-OH should not be neglected as it may attract $\mathrm{Ca}^{+2}$ ions in $1.5 \times \mathrm{c}$-SBF by Coulomb force too, or combine phosphate ions in $\mathrm{TiOH}-\mathrm{HPO}_{4}$ by covalent bonding. But in this case, the surface electricity should not be the main factor affecting the nucleation of calcium phosphate. So, the precalcification of titanium with saturated $\mathrm{Ca}(\mathrm{OH})_{2}$ solution accelerated the precipitation of calcium phosphate on titanium surfaces, and precipitation of phosphate ions should be prior to calcium ions.

\section{Electrical Conductivity Measurements}

The electrical conductivity values for soaking solutions at successive periods would account to ionic concentrations in such supersaturated solutions. As the ionic concentration decreases by uptake from solution and/or deposition onto the sample surface, the conductivity of the solution will decrease as a whole and vice versa. Thus, any reduced ionic concentration in SBF due to the depositions on the alloy surface would appear as a reduction in conductivity values and is represented as increased decrements and vice versa. These measurements are valuable as they succeeded to give the mirror image for those of the calcium and phosphorus ionic concentrations.

\section{CONCLUSIONS}

The alkali and heat treatment of the Ti-6Al-4V alloy alone lead to the growth of nonuniform HA on the sample surface after subsequent biomimetic coating. The optical density of the resultant phase reflects the slow rate of calcium phosphate precipitations on the alloy surface. On the other hand, precalcification, in particular $\mathrm{Ca}(\mathrm{OH})_{2}$ treatment, lead to the deposition of a uniform calcium precursors on the alloy surface and accelerated the growth of carbonate apatite after subsequent biomimetic coating in $1.5 \times \mathrm{c}-\mathrm{SBF}$.

The suggested protocol of pretreatments as a whole succeeded to produce a biomimetic coat on the sample surfaces after soaking in the present SBF.

The diffuse reflectance FT-IR spectroscopy was valuable as non invasive follow up technique to follow the behavior of deposition. The adopted Ac electrical conductivity measurements of the soaking solutions post immersions succeeded to give the complementary information about the deposition rate on the sample surface.

\section{ACKNOWLEDGEMENT}

The authors acknowledge the financial support of Ain Shams University and National Research Centre for the master thesis of Miss Alaa Adawy, at Physics department, Faculty of Science, Cairo, Egypt.

\section{REFERENCES}

[1] Sittig C, Textor M, Spencer ND, Wieland M, Vallotton PH. Surface characterization of implant materials c.p.Ti, Ti-6Al-7Nb and Ti-6Al-4V with different pretreatments. J Mater Sci Mater Med 1999; 10: 35-46.

[2] Liu X, Zhao X, Fu Ricky KY, Joan PY Ho, Chuanxian D, Paul KC. Plasma-treated nano-structured $\mathrm{TiO} 2$ surface supporting biomimetic growth of apatite. Biomaterilas 2005; 26: 6143-50.

[3] Nishiguchi S, Nakamura T, Kobayashi M, Miyagi F, Kokubo T. Studies on a novelbioactive glass and composite coating with hydroxyapatite on titanium based alloys: Effect of $\gamma$-sterilization on coating. Biomaterials 1999; 20: 491-500.

[4] Lin J-H, Chang C-H, Chen Y-S, Lin G-T. Formation of bone -like apatite on titanium filaments by a simulated body inducing process. Surf Coat Technol 2003; 200: 3665-9.

[5] Slenes K, Ackerman WC, Brotzman RW, Stoltzfux J, Gunaji M. Ceramic coatings that increase wear resistance and suppress the ignition of 316 stainless steel in an oxygen environment. Surf Coat Technol 1994; 51-7.

[6] Albers L. Bioresorbable ceramics: Titanium as a biomaterial. 2004.

[7] Johnson S. Pulsed Laser Deposition of Hydroxyapatite Thin Films. M.Sc. thesis, Georgia Institute of Technology 2005.

[8] Kokubo T, Kim H, Kawashita M. Novel bioactive materials with different mechanical properties. Biomaterials 2003; 24: 2161-75.

[9] Yan W-Q, Nakamura T, Kawanabe K, Nishigochi S, Oka M, Kokubo T. Apatite layer-coated titanium for use as bone bonding implants. Biomaterials 1997; 18: 1185-90.

[10] Lin F-H, Hsu Y-S, Lin S-H, Chen T-M. The growth of hydroxyapatite on alkaline treated $\mathrm{Ti}-6 \mathrm{Al}-4 \mathrm{~V}$ soaking in higher temperature with concentrated $\mathrm{Ca}^{2+} / \mathrm{HPO}_{4}{ }^{2-}$ simulated body fluid. Mater Chem Phys 2004; 87: 24-30.

[11] Xie Y, Liu X, Paul K, Chu, Ding C. Nucleation and growth of calcium-phosphate on Ca-implanted titanium surface. Surf Sci 2006; 600: 651-6.

[12] Wen HB, Wolke JGC, de Wijn JR, Liu Q, Cui FZ, de Groot K. Fast precipitation of calcium phosphate layers on titanium induced by simple chemical treatments. Biomaterials 1997; 18: 1471-8.

[13] Feng B, Chen JY, Qi SK, He L, Zhao JZ, Zhang XD. Carbonate apatite coating on titanium induced rapidly by precalcification. Biomaterials 2002; 23:173-9.

[14] Kokubo T, Takadama H. How useful is SBF in predicting in vivo bone bioactivity? Biomaterials 2006; 27: 2907-15. 
[15] Jalota S, Bhaduri S, Bhaduri B, Tas AC. A protocol to develop crack-free biomimetic coatings on Ti6Al4V substrates. J Mater Res 2007; 22: 1593-600.

[16] Barrere F, van Blitterswijk CA, de Groot K, Layrolle P. Nucleation of biomimetic $\mathrm{Ca}-\mathrm{P}$ coatings on Ti6Al4V from a $\mathrm{SBF} \times 5$ solution: influence of magnesium. Biomaterials 2002; 23: 2211-20.

[17] Rigo CS, Boschi AO, Yoshimoto M, Allegrini Jr S, Konig Jr B, Carbonari MJ. Evaluation in vitro and in vivo of biomimetic hydroxyapatite coated on titanium dental implants. Mater Sci Eng C 2004; 24: 647-651.

[18] Chou Y-F, Chiou W-A, Yuhuan X, Dunn JCY, Benjamin M Wu. The effect of $\mathrm{pH}$ on the structural evolution of accelerated biomimetic apatite. Biomaterials 2004; 25: 5323-31.

[19] Ng BS, Annergren I, Soutar AM, Khor KA, Jarfors AEW. Characterisation of a duplex $\mathrm{TiO}_{2} / \mathrm{CaP}$ coating on $\mathrm{Ti} 6 \mathrm{Al} 4 \mathrm{~V}$ for hard tissue replacement. Biomaterials 2005; 26:1087-95.

[20] Müller L, Müller FA. Preparation of SBF with different $\mathrm{HCO}_{3}{ }^{-}$ content and its influence on the composition of biomimetic apatites. Acta Biomater 2006; 2: 181-9.

[21] Murugan R, Ramakrishna S. Production of ulta-fine bioresorbable carbonated hydroxyapatite. Acta Biomater 2006; 2: 201-6.

[22] Hu K, Yang X-J, Cai Y-L, Cui Z-D, Wei Q. Preparation of bonelike composite coating using a modified simulated body fluid with high Ca and P concentrations. Surf Coat Technol 2006; 201: 19026.

[23] Lnadi E, Tampieri A, Celotti G, Sprio S, Sanri M, Logroscino G. Sr- substituted hydroxyapatites for osteoporotic bone replacement. Acta Biomater 2007; 3: 961-9.

[24] Smith B. Infrared spectral interpretation. A systematic approach. CRC Press 1998.

[25] Li Z.Y, Lam WM, Yang C, Xu B, Ni GX, Abbah SA, Cheung KMC, Luk KDK, Lu WW. Chemical composition, crystal size and lattice structural changes after incorporation of strontium into biomimetic apatite. Biomaterials 2007; 28:1452-60.

[26] Bayraktar D, Tas AC. Chemical preparation of carbonated calcium hydroxyapatite powders at $37^{\circ} \mathrm{C}$ in urea-containing synthetic body fluids. J Eur Ceram Soc 1999; 19: 2573-9.

[27] Barrere F, Layrolle P, van Blitterswijk CA, de Groot K. Biomimetic coatings on titanium: a crystal growth study of octacalcium phosphate. J Mater Sci Mater Med 2001; 12: 529-34.

[28] Habibovic P, Barrere F, van Blitterswijk Clemens A, de Groot K, Layrolle P. Biomimetic hydroxyapatite coating on Metal implants. J Am Ceram Soc $2002 ; 85$ : 517-22.
[29] Oliveira AL, Reis RL, Li P. Strontium-substituted apatite coating grown on Ti6Al4V substratethrough biomimetic synthesis. J Biomed Mater Res Part B: Appl Biomater 2007; 83B: 258-65.

[30] Jalota S, Bhaduri SB, Tas AC. Effect of carbonate content and buffer type on calcium phosphate formation in SBF solutions. J Mater Sci Mater Med 2006; 17: 697-707.

[31] Li P, Ohtsuki C, Kokubo T, Nankanishi K, Soga N, de Groot K. 1994. Role of hydrated silica, titania, and alumina in inducing apatite on implants. J Biomed Mater Res 1994; 28: 7-15.

[32] Ito A, Sogo Y, Yuko E, Masahiro O, Ayako O, Noboru I. Formation of an ascorbate-apatite composite layer on titanium. Biomed Mater 2007; 2: 181-5.

[33] Wang J, layrolle P, Stigter M, De Groot K. Biomimetic and electrolytic calcium phosphate coatings on titanium alloy: physicochemical characteristics and cell attachment. Biomaterials 2004; 25: 58392.

[34] Bharati S, Sinha MK, Basu D. Hydroxyapatite coating by biomimetic method on titanium alloy using concentrated SBF. Bull Mater Sci 2005; 28: 617-21.

[35] Jia-Horng L, Chia-Hao C, Yueh-Sheng C, Gau-Tyan L. Formation of bone -like apatite on titanium filaments by a simulated body inducing process. Surf Coat Technol 2006; 200: 3665-9.

[36] Jia-Horng L, Chia-Hao C, Yueh-Sheng C, Gau-Tyan L. Formation of bone-like apatite on titanium filaments incubated in a simulated body fluid by using an electrochemical method. Compos Part A Appl Sci Manu 2007; 38: 535-9.

[37] Teixeira R, Perez L, de Godoy GCD, Pereir M. Calcium phosphate formation on alkali-treated titanium alloy and stainless steel. Mater Res 2004; 7: 299-303.

[38] Tas AC, Bhaduri SB. Rapid coating of Ti6Al4V at room temperature with a calcium phosphate solution similar to $10 \times$ simulated body fluid. J Mater Res 2004;19: 2742-9.

[39] Tas AC. Electroless deposition of brushite $\left(\mathrm{CaHPO}_{4} \cdot 2 \mathrm{H}_{2} \mathrm{O}\right)$ crystals on Ti-6Al-4V at room temperature. J Mat Res 2006; 97: 639-44.

[40] Lu X, Wang Y-bo, Liu Yu-rong, Wang Jian-xin, Qu Shu-xin, Feng Bo, Weng Jie. Preparation of HA/chitosan composite coatings on alkali treated titanium surfaces through sol-gel techniques. Mater Lett 2007; 61: 3970-3.

[41] Li S J, Yang R, Niinomi M, Hao YL, Cui YY. Formation and growth of calcium phosphate on the surface of oxidized ti-29nb13ta-4.6zr alloy. Biomaterials 2004; 25: 2525-32.

(C) Adawy et al.; Licensee Bentham Open.

This is an open access article licensed under the terms of the Creative Commons Attribution Non-Commercial License (http://creativecommons.org/licenses/by-nc/3.0/) which permits unrestricted, non-commercial use, distribution and reproduction in any medium, provided the work is properly cited. 